\title{
Todd J. Albert, Joon Yung Lee, Moe R. Lim (eds): Cervical spine surgery challenges diagnosis and management
}

\author{
Thieme Verlag, New York, Stuttgart, 2008, 260 pp, 180 figures, Hardcover, \\ Euro (D) 119.95 CHF 199.00, ISBN: 978-3-13-142551-5
}

Pierre Kehr

Received: 28 February 2010 / Accepted: 1 March 2010 / Published online: 13 March 2010

(C) Springer-Verlag 2010

The surgery of the cervical spine is as demanding as it is gratifying and constitutes a very particular interest for this reason. The American authors offer to us a panorama of readily pointed subjects concerning the cervical spine surgery, thanks to didactic and synthetic presentations. Indeed, each chapter is built according to the same plan: put presentation, background, then the preferred author salary with the technique, the post-operative care, the complications and the other methods. In margin, one finds very invaluable pearls and pitfalls. All the fields of spine diseases are approached: degenerative, inflammatory and infections conditions, neoplasms, injuries, deformity, and miscellaneous. The iconography, in black and white, is very conclusive.

Even if the treatments carried out can be discussed, this work must be recommended to experienced surgeons specialized in spine diseases.

Laurent Balabaud Paris (France)

No funds were received in support of this study. 